\title{
Reproduction based Multi-Contents Distribution Platform
}

\author{
Byung-Duck Lee ${ }^{1}$, Keun-Ho Lee ${ }^{2}$, Seong-Soo Han ${ }^{3}$, and Chang-Sung Jeong ${ }^{4 *}$ \\ ${ }^{1}$ Department of Visual Information Processing, Korea University, Seoul, South Korea \\ [e-mail: leesanta77@gmail.com] \\ ${ }^{2}$ Division of ICT Baekseok University, Cheonan, South Korea \\ [e-mail: root1004@bu.ac.kr] \\ ${ }^{3}$ Dept. of Division of Liberal Studies, Kangwon National University, Samcheok, South Korea \\ [e-mail: sshan1@kangwon.ac.kr] \\ ${ }^{4}$ Dept. of Electrical Engineering, Korea University, Seoul, South Korea \\ [e-mail: csjeong@korea.ac.kr] \\ *Corresponding author: Chang-Sung Jeong
}

Received September 14, 2020; revised October 26, 2020; accepted November 23, 2020; published February 28, 2021

\begin{abstract}
As the use of smart devices is being increased rapidly by the development of internet and IT technology, the contents production and utilization rate are showing higher increase, too. In addition, the type of contents also shows very diverse forms such as education, game, video, UCC, etc. In the meantime, the contents are reproduced in diverse forms by reprocessing the original contents, and they are being serviced through the contents service platform. Therefore, the platform to make the contents reprocessing easy and fast is needed. As the diverse contents distribution channels such as YouTube, SNS, App Service, etc, easier contents distribution platform is needed, and the development of the relevant area is expected. In addition, as the selective consumption of the contents having easy accessibility through diverse smart devices is distinguished, the demand for the platform and service that can identify the contents consumption propensity by individual is being increased. Therefore, in this study, to vitalize the online contents distribution, the contents reproduction and publishing platform, was designed and materialized, which can reproduce and distribute the contents based on the real-time contents editing technology in URL unit and the consumer propensity analysis technology using the data management-based broadcasting contents distribution metadata technology and the edited image contents streaming technology. In addition, in the results of comparing with other platforms through the experiment, the performance superiority of the suggested platform was verified. If the suggested platform is applied to the areas of education, broadcasting, press, etc, the multi-media contents can be reproduced and distributed easily, through which the vitalization of contents-related industry is expected.
\end{abstract}

Keywords: Digital Contents, Metadata, Contents Reproduction, Contents Distribution, Publishing Platform

A preliminary version of this paper was presented at APIC-IST 2020, and was selected as an outstanding paper. This research was supported by Basic Science Research Program through the National Research Foundation of Korea(NRF) funded by the Ministry of Education(NRF-2020R1I1A3069008) 


\section{Introduction}

In the era of 4th industrial revolution, the contents consumption is being expanded enough to call it as sea of contents by the use of diverse types of computer and smart devices together with the rapid development of IT technology and internet [1]. The market size of the digital information contents marked approximately 249 billion 127 million dollar in 2017 showing high increase rate in the major countries of United States, China, Japan, etc. and the future digital contents market would be approximately 345 billion 549 million dollar by 2022 due to expansion of the IT infrastructure and smart phone distribution expecting that the market size would be grow up rapidly. In addition, the type of contents is showing diverse forms such as entertainment, education, UCC (User Create Content), article, video, etc. In the meantime, the contents are reproduced in diverse forms by reprocessing the original contents and are serviced through the contents service platform. The size of world digital contents solution market also marked approximately 201 billion 966 million dollar in 2018and is expected to grow up 272 billion 720 million dollar by 2022 [2].

Recently, the attempt to distribute the contents online is made a lot through diverse media platform. However, in case of video contents, there are problems that the metadata standard is different by the production company and there should be reprocessed as new type of contents fit to the video portal service or OTT (Over The Top) service. To solve these problems, diverse platforms having the function to produce and distribute the same contents are researched in various service sites $[3,4]$.

In case of broadcasting contents, the standardization of metadata has been made to make the distribution and service more efficiently among the contents provider, distribution platform and service provider so that the contents produced in the broadcasting station, production, etc. can be provided in diverse contents through the online contents service $[5,6]$. As diverse multimedia APP services are being developed matching with the fast speed of 5G wireless network and the development speed of mobile device and many multimedia contents are generated and processed proportionally in real-time, the importance of the standardized management of the meta information and of the convenient reprocessing of multimedia and the distribution of publishing contents is being increased [7-9].

In this study, the multimedia reproduction and distribution platform, which the management of the standardized metainformation, the convenient reproduction of the multimedia and application of the attribute metadata when uploading the video contents, and the test was performed to see if the functions of generating, editing and distributing the contents to the service site and consumption propensity analysis, etc. were working normally. In addition, the excellence of the suggested platform was verified by comparing and analyzing the performance with the existing platform of other company. Through the development outcome obtained from this study, the digital contents distribution platform technology was secured and it is expected to contribute not only to the vitalization of online contents consumption but also to the conversion and reproduction of the contents and to the creation of new industry related to the contents distribution by being utilized in the future contents distribution market.distribution of the publishing contents are possible, was intended to design and materialize. The major functions of the suggested platform can be divided mainly into 3 functions. First is the metadata function of the video contents to vitalize the online distribution of the contents, Through this function, the system that can register and manage the meta information, which becomes the standard of the multimedia contents, can be materialized. Second is the editing function that can split and integrate the contents in URL unit in real-time using streaming technology without downloading the contents subject to edit. Finally, the 
system having function to analyze the consumption propensity utilizing the information of user's viewing history will be made [10-12].

For the performance evaluation of the suggested reproduction-based publishing platform, the load test for the function screens of the platform was performed, the major performance indicators were the response time within average 1 second and automatic extraction and

\section{Related Work}

\subsection{Component and Format of Broadcasting Contents Distribution Metadata}

TTA (Telecommunication Technology Association) defined the contents as it refers to the tangible or intangible information or outcome made by creating "the text, symbol, voice, sound, image, video, etc. and the broadcasting contents as it means including the essence and the metadata. The metadata standard items cover the range that standardizes the items used commonly in the contents distribution process [5]. Table 1 shows the metadata element and the format of distribution metadata comprising TTA broadcasting contents distribution.

Table 1. Metadata element and format for Broadcasting content distribution

\begin{tabular}{|c|c|c|c|c|}
\hline PROGRAM & EPISODE & SEGMENT & $\begin{array}{c}\text { DISTRIBUTION } \\
\text { _CONTENT } \\
\text { /ESSENCE }\end{array}$ & PUBLIC \\
\hline $\begin{array}{l}\text { Program_code } \\
\text { Program_title } \\
\text { Program_objective } \\
\text { Synopsis } \\
\text { Program_genre } \\
\text { Program_genre } \\
\text { _sub } \\
\text { Homepage_URL } \\
\text { Search_keyword } \\
\text { Program_start } \\
\text {-date } \\
\text { Program_end } \\
\text {-date } \\
\text { Program_end } \\
\text {-YN } \\
\text { Onair_day } \\
\text { Episode_count } \\
\text { Broadcast_station }\end{array}$ & $\begin{array}{l}\text { Program_code } \\
\text { Episode_ID } \\
\text { Subtitle } \\
\text { Episode_sequence } \\
\text { _number } \\
\text { Storyline } \\
\text { Search_keyword } \\
\text { Clean_picture } \\
\text { _YN } \\
\text { Programming } \\
\text { _date } \\
\text { Programming } \\
\text { _start_date } \\
\text { Program_start } \\
\text { _time } \\
\text { Program_end } \\
\text { _time } \\
\text { Program } \\
\text { _duration } \\
\text { minute }\end{array}$ & $\begin{array}{l}\text { Episode_ID } \\
\text { Segment_code } \\
\text { Segment_ID } \\
\text { Segment_order } \\
\text { Segment_title } \\
\text { Segment } \\
\text { _contents }\end{array}$ & $\begin{array}{l}\text { Distribution } \\
\text { content_ID } \\
\text { Content_title } \\
\text { Episode_ID } \\
\text { Segment_ID } \\
\text { Media_URL } \\
\text { Video_codec } \\
\text { Video_bitrate } \\
\text { File_format } \\
\text { File_size } \\
\text { Duration }\end{array}$ & $\begin{array}{l}\text { Name_korean } \\
\text { Broadcast_person } \\
\text { _classification } \\
\text { Cast_name } \\
\text { Production } \\
\text { _company } \\
\text { Production } \\
\text { _place } \\
\text { Production } \\
\text { _nationality } \\
\text { _code } \\
\text { Program } \\
\text { _deliberation } \\
\text { _grade } \\
\text { Production } \\
\text { _language } \\
\text { Broadcast } \\
\text { _language } \\
\text { Language } \\
\text { code }\end{array}$ \\
\hline
\end{tabular}

\subsection{Analysis of Metadata Structure for Online Video Editing}

To provide the function to edit and combine the online media contents, the information on the media attribute is needed for the rendering according to the accurate codec information of the media. In this study, the metadata was analyzed using Mediainfo program, which can extract the accurate metadata of the media image automatically. Media metadata was extracted in the XML format using Mediainfo program. The information extracted is the format, formatVersion, Duration, OverallBitRate, EncodeDate, Application, Library, video:Format, FormatInfo, FromatProfile, FormatSettings, Duration, RateControl, AvgBitrate, MaxBitrate, 
BitRate, Width, Hight, AspectRateMode, FrameRate, ColorSpace, ChromaSubsampling, BtDepth, ScanType, StreamSize, Library, EcodingSettings, ColorRange, MatrixCoefficients, Audio:Format, FormatInfo, Duration, BitRate, Channels, ChannelPositions, SamplingRate, FrameRate, Bitdepth, CompressionMode and StreamSize are extracted [13]. Fig. 1 shows the screen of extracting media metadata using Mediainfo.

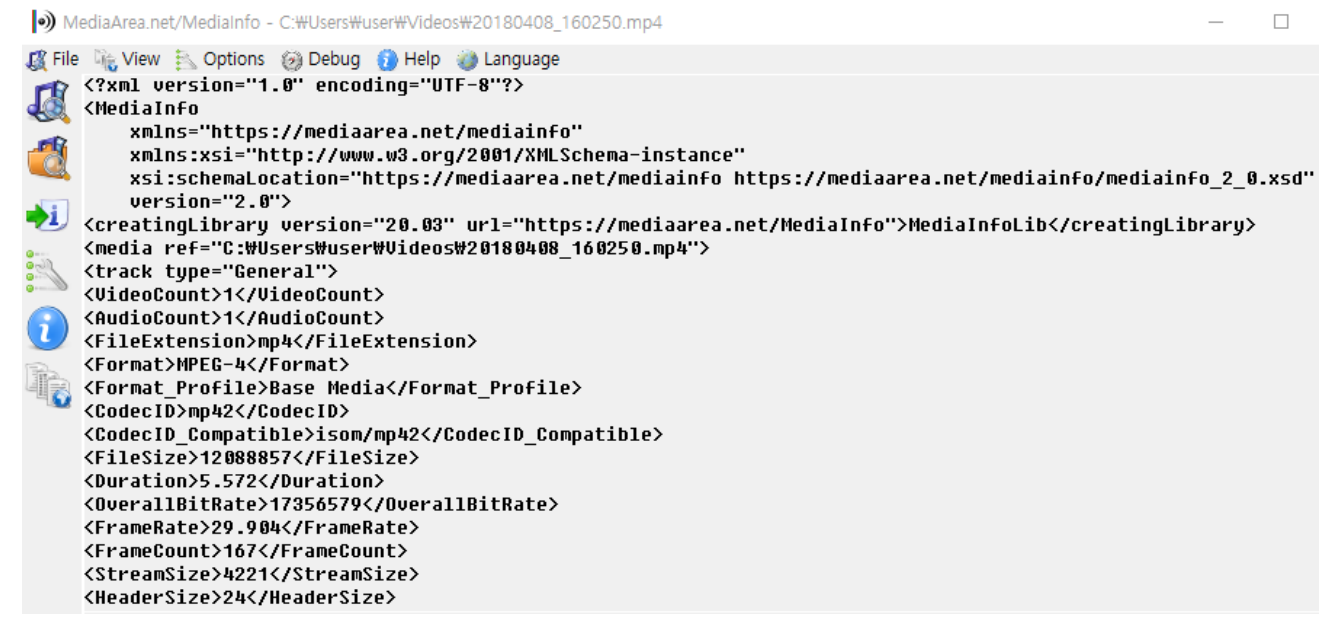

Fig. 1. Example of extracting media metadata using Mediainfo

\subsection{Real-time Online Editing Technology}

For the tool to edit video file, in case of commercial video media, Premiere by Adobe and Vegas by Sony, which are used for the professional video editing, are representative, and in case of using it simply, Movavi by Video Toolbox, etc. are used [9]. In this study, to make and edit the contents to be serviced online, FFMPEG was used. As the computer program to record and convert the digital voice stream and video stream in diverse formats, FFMPEG is working by entering the command directly and composed of various free software and open source library. FFMPEG provides the functions to split the video fit to the service or to edit it in the several video media. In addition, it distributes the edited contents by regenerating in service document in HTML format. In case of video media, if FFMPEG is used, the video can be edited online in real-time together with the function to edit and distribute the video to the service like YouTube [14].

FFMPEG is the video editing library developed under the leadership by Michael Niedermayer. It uses the software type encoding, which records and converts the digital voice stream and video stream in diverse types of format. FFMPEG operates in the way that inputs the command directly and is composed of open source library. In the library, there are FFmpeg, which is the media format conversion tool, Libavcodec, which functions as media codec, Libavfilter, which has the function of media filter, Libavformat, which functions as multimedia container mixer/remixer, Libavdevice, which has function to control the input and output device, Libswresample, which functions to process the audio, etc, and this library is used in various projects as the voice and video codec library.

The method of using basic FFMPEG command is as follows, \#FFMPEG-I [INPUT] -c:v[video codec] -c:a[audio codec] [OUTPUT]

And if the video editing is made based on the time, the video is edited using following command [14]

\#FFMPEG-I[INPUT] -ss 00:00:00 -t 00:01:00 -c:v libx264 -c:a libfdk_aac OUTPUT] 


\subsection{Research for Consumer Propensity Analysis}

As the contents service is vitalized, large amount of contents are generated and the algorithms that analyze the contents propensity of the consumer and recommend the similar contents are under research. The representative cases that utilize such algorithm are the movie recommendation service of Netflix, which is the video service, the merchandise recommendation service of Amazon, the contents recommendation similar to the contents already viewed in YouTube, which is UCC contents, etc. and such services provide the service by analyzing the consumption propensity according to the contents consumption of the consumers [12].

In the recommendation system, mainly the user-based collative filtering, which based on the similarity among the users, and the content-based filtering, which is based on the similarity of contents, are being used. The general method to obtain the similarity is to obtain the cosine similarity of two vectors [15-17].

The algorithms that recommend by similarity, whether user-based or content-based, basically provide the recommendation through the type analysis of the contents preferred by certain user. This study has a purpose of providing the multi-contents to service provider and approached with the method of analyzing the contents using the content user's information.

\section{Platform Design and Materialization}

In this study, the platform to develop the reproduction-based publishing platform technology, which can reproduce and distribute the contents based on the standard-based broadcasting contents distribution metadata management for the vitalization of online content distribution, on the technology to edit the contents by URL unit online using the streaming technology without downloading the contents subject to edit and on the viewer's consumption propensity analysis technology, was designed as shown in Fig. 2.

The platform was designed by dividing it into the areas of Content Data Manager, which can manage the multimedia contents, Webeditor Manager, which can edit the video contents, Publishing Manager, which makes the multi-contents into the distributable data, Interface Manager, which can manage the interface format in order to distribute the reproduced contents in the external site, and Report Manager, which allow the user to be able to manage the media information. In the content data manager area, Multimedia Manager, which can manage the text, video, image, etc, Provider Manager, which can manage the contents provider, and Mapping manager, which can manage the metadata items used as a standard of the Metadata Manager in order to manage the media information of the contents and can manage the contents metadata obtained through that, were designed. Webeditor Manager, which can edit the video contents, was designed in order to edit using JWplayer and FFMPEG allowing that it can play back and edit the video content. Publisher Manager, which generates the publishing data using each registered text, video and image so that they can be used in the portal, video service or SNS service, was designed and the reproduced contents made as such distributes the contents to the external link sites registered in Interface Manager. The contents provided as such deliver the information to the contents user in each service site and if relevant contents are clicked and used, the information is returned to Report Manager in order to analyze the user information and the contents information of the relevant contents. Report Manager allows the contents that the users want to be reproduced by analyzing the returned information. Fig. 2 shows the block diagram configuration of the platform by function. 


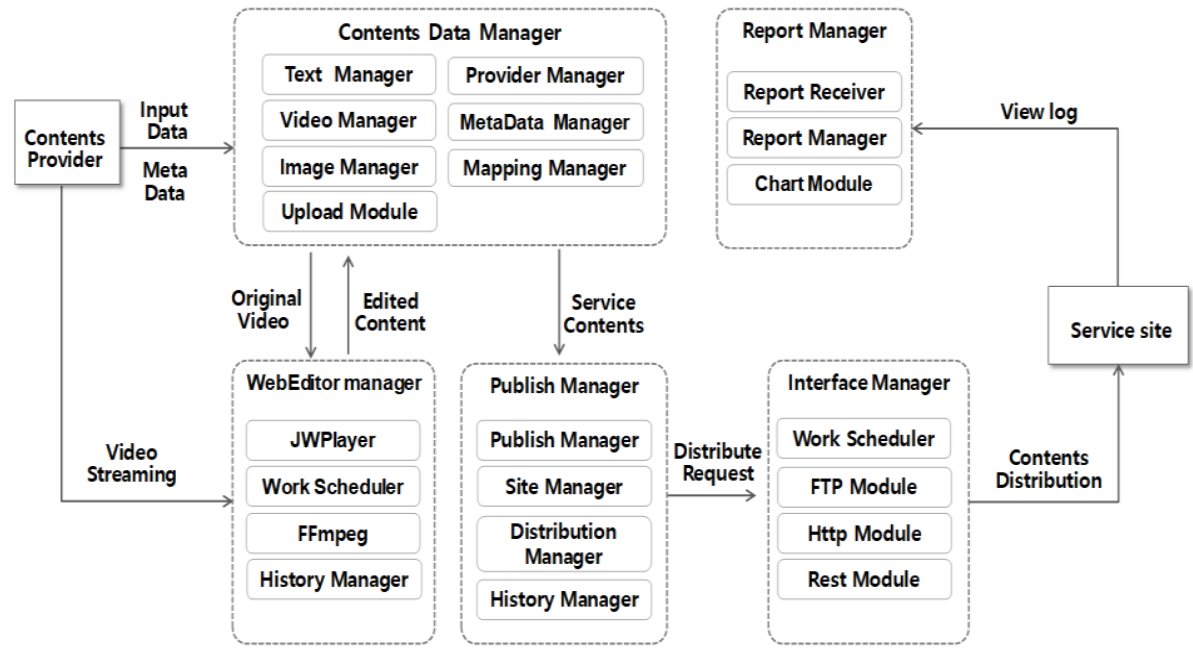

Fig. 2. Block Diagram Configuration of Platform by Function

\subsection{Conversion and Generation of Distribution Standard Metadata}

In the stage of collecting the contents, the basic information of the contents can be obtained from the contents provider with xml DATA and the screen to input the meta-information delivered was designed. In case of video, it was designed that the media attribute is extracted and saved automatically when uploading the content through the mediainfo program of the video. In the stage of acquiring the contents, it was designed to process the contents such as article, video and image, etc. and to make the new contents, the text manager was designed to register, save and correct the text using text editor. The image manager was designed to register and manage the image and it saves the metadata extracted with mediainfo application program in the contents media information database. In case that the metadata information is obtained in advance with metainformation $\mathrm{xml}$ file when acquiring the contents, the metadata information is registered in the platform so that metadata information can be managed automatically using xml parser when uploading the files as shown in Fig. 3 [18].

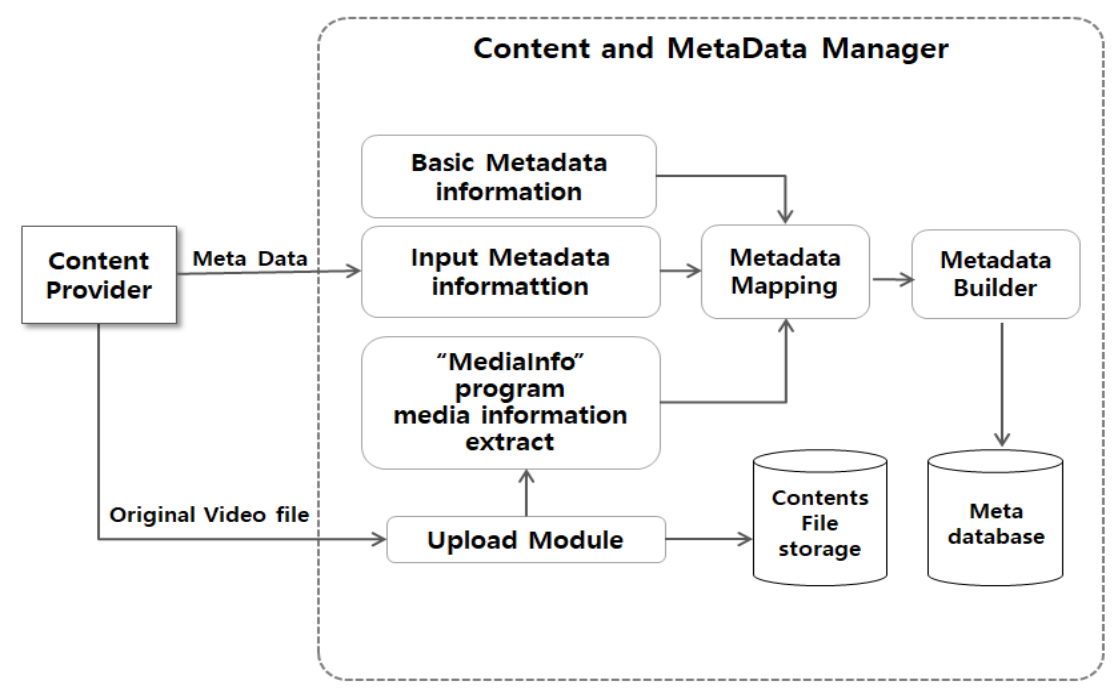

Fig. 3. Metadata Creation Configuration 
The video file uploaded is saved in the content file storage and all the information of the metadata used as standard of contents are managed as field in the database, the information, which use the information with same meaning differently by content, define the mapping of each metafield through the mapping builder and are provided as linked metadata xml format data during external link. Fig. 4 shows the screen that manages the metadata and registers the metainformation and it provides the function to manage the metainformation of various items registering the metainformation to be managed as standard and adding the metainformation generated newly.

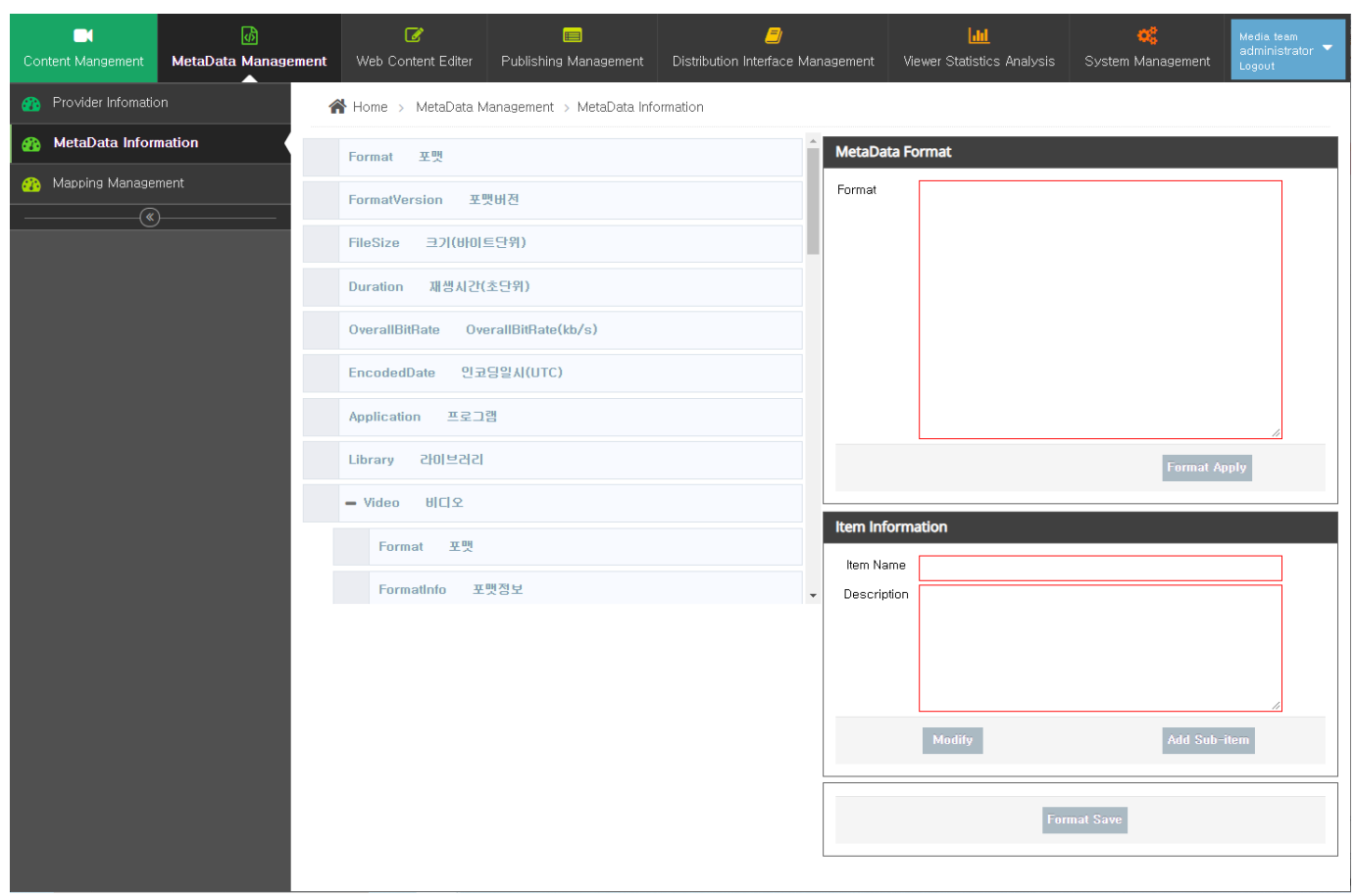

Fig. 4. Metadata Item Management Screen

\subsection{URL-based Web Editing of Contents}

Most of the video contents editing technologies use the editing method that download and save the contents subject to edit physically in the local PC and edit the saved contents using Premiere or Vegas, which is the editing program. In this study, the simple editing function was designed, which splits the video contents in URL in real-time and combines various videos by combining streaming technology and editing technology without saving the contents subject to edit in the local storage.

In case of video editing, there are the cases that lot of editing are made such as inserting subtitle, animation, etc. beside the splitting and combining the video file but the function pursued by this study is the function to split and merge with simple editing and was designed and materialized in order to edit online easily. 


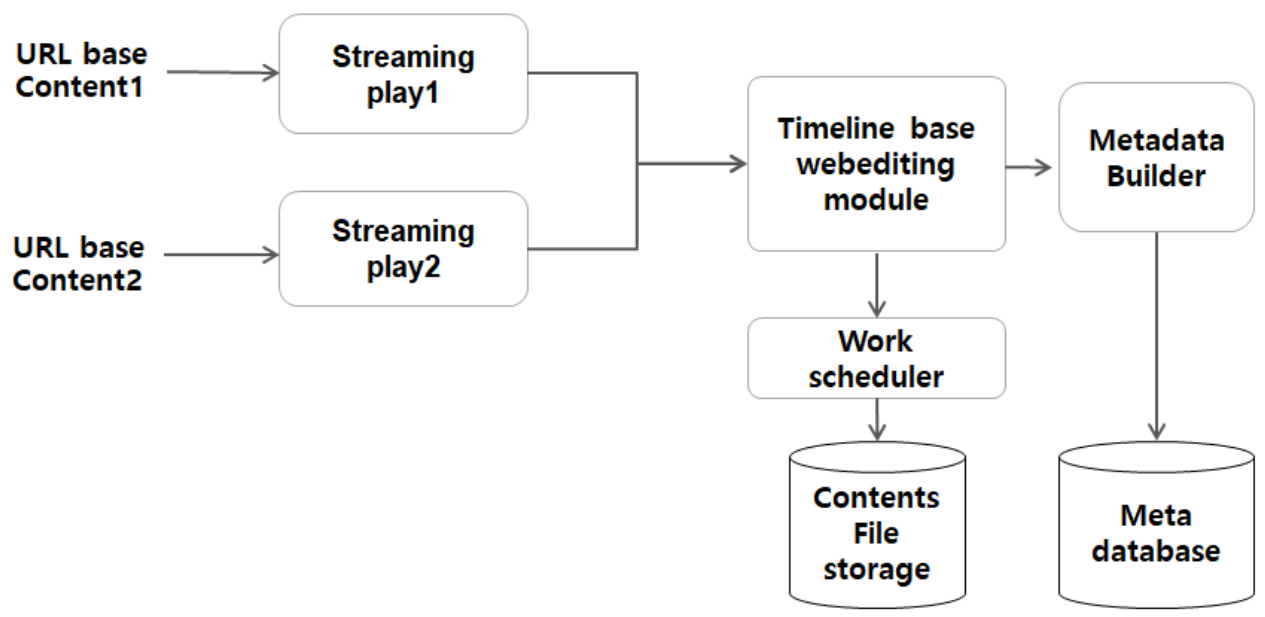

Fig. 5. URL- based Content Editing Module Dataflow

As shown in Fig. 5, it was designed so that the URL-based editing of contents is possible by entering the address of online web URL contents in order to search the video online. The editing function, which splits the one content in real-time in the form of clip video and combining two videos by setting time interval by video. In the function to edit the video, the relevant content is managed so that FFMPEG can work in order by managing the work schedule information to be edited. The video content edited is saved in the file storage and provided as reproduced contents to the metadata of relevant contents. Fig. 6 shows the screen that the relevant content is materialized.

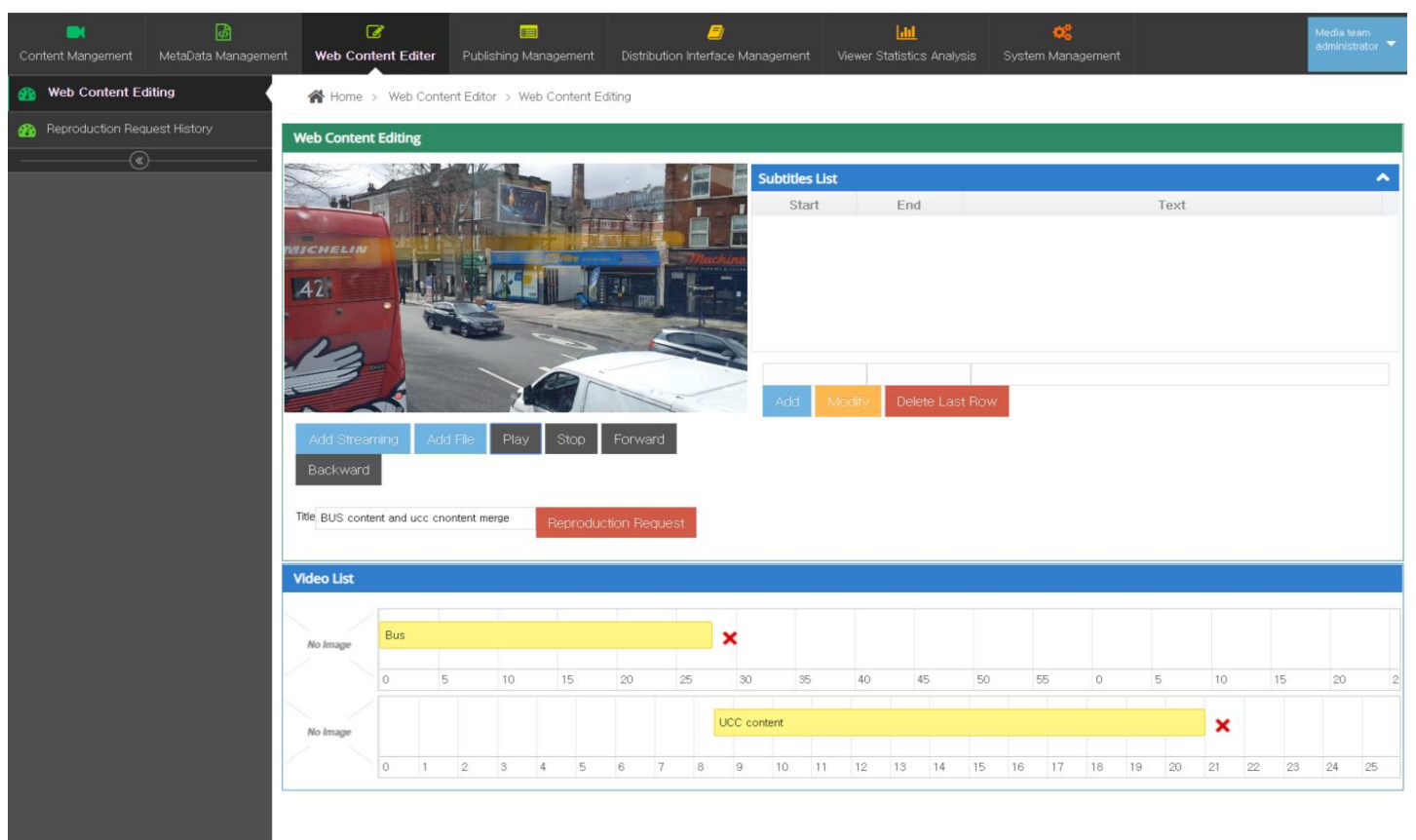

Fig. 6. URL-based Real-Time Video Content Editing Screen 


\subsection{Content Distribution and Content View Analysis Function}

The contents registered in advance such as article, image, video, etc. are defined as the publishing content type in the format fit to the service type such as video + image, image + article, video + image + text, etc. through the publishing format editor of the publish manager and are reproduced as service contents through the publishing format editor fit to the established rules. Reproduced contents are distributed to the target site in the distribution screen according to the distribution command, and the distribution manager manages the metadata, etc. to be transmitted together with link information, the basic linked items, FTP address, port, ID, PWD, location and content file to the linked site of the service provider fit to the link size in the platform. As shown in below Fig. 7, the contents are reproduced, distributed to the service site and returns the viewed information of the distributed contents in the service site.

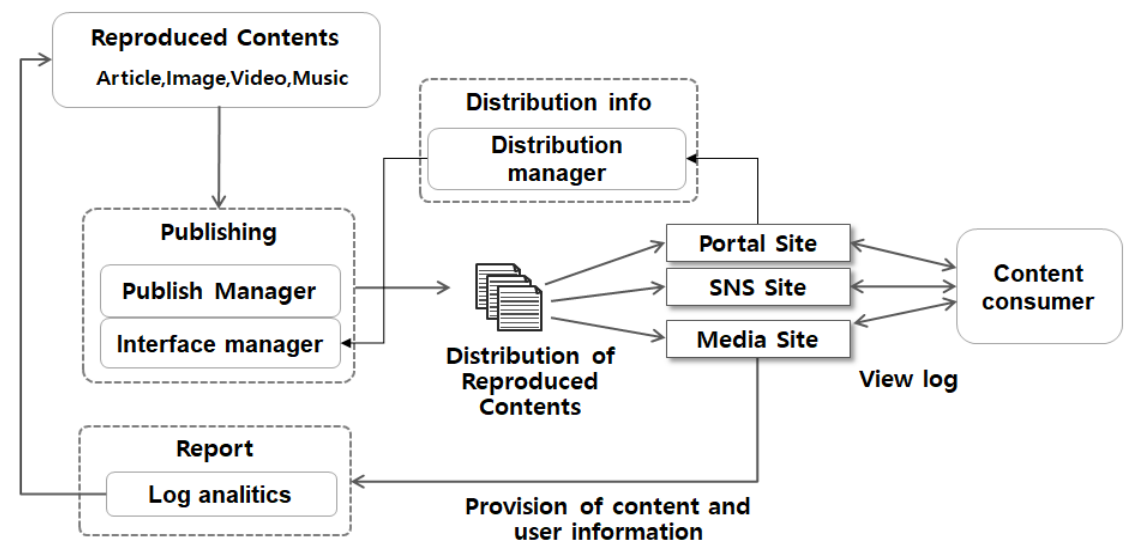

Fig. 7. Distribution of Reproduced Publishing Contents and Log Analysis Dataflow

Below Fig. 8 is the screen that generates the contents to be distributed to the service provider in the publishing format editor and to make publishing contents by combining the contents of video, image and article.

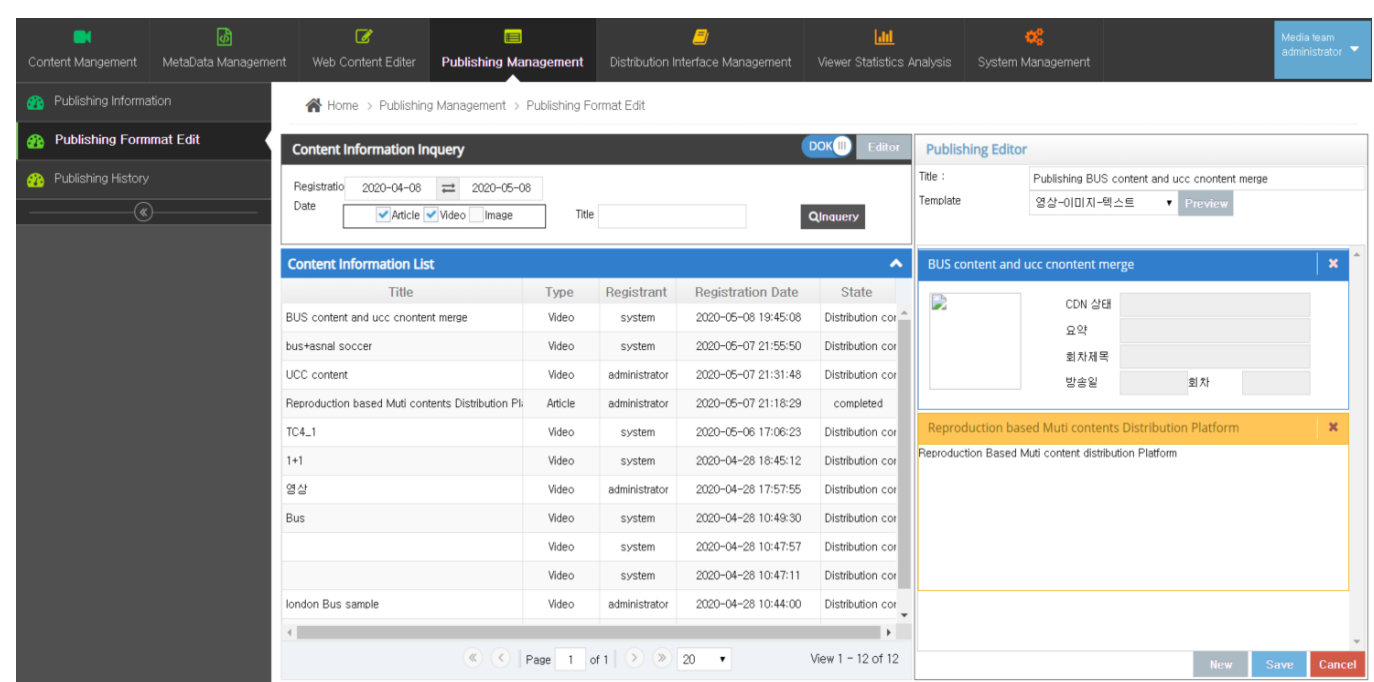

Fig. 8. Reproduced Content Generation Screen using Publishing Format 
Fig. 9 shows the screen of mapping metadata that the service provider actually wants to use.

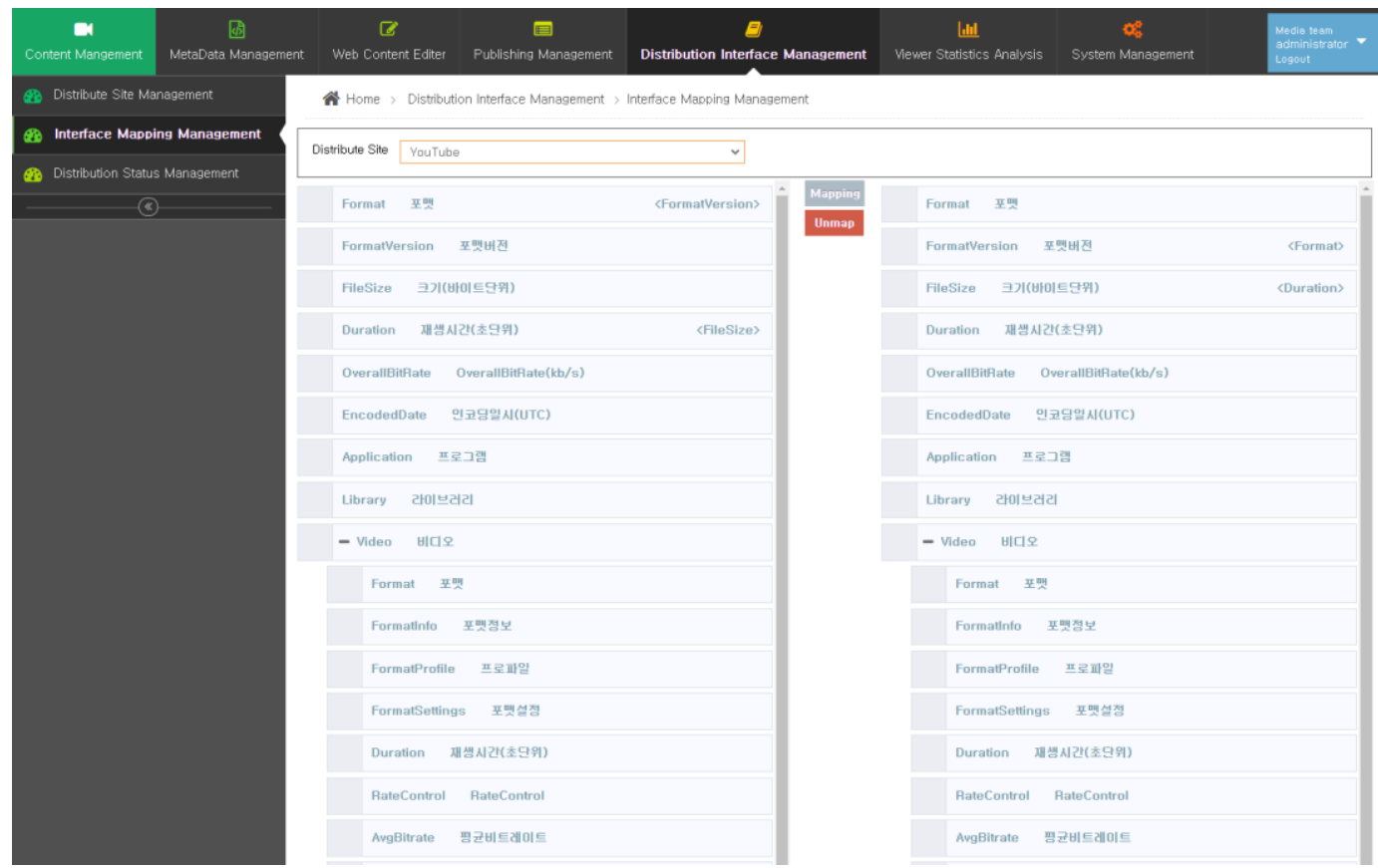

Fig. 9. Metadata Format Generation Screen through Distribution Mapping Data

Fig. 10 shows the screen that manages the information on the link to be used when sending the reproduced content to the service provider.

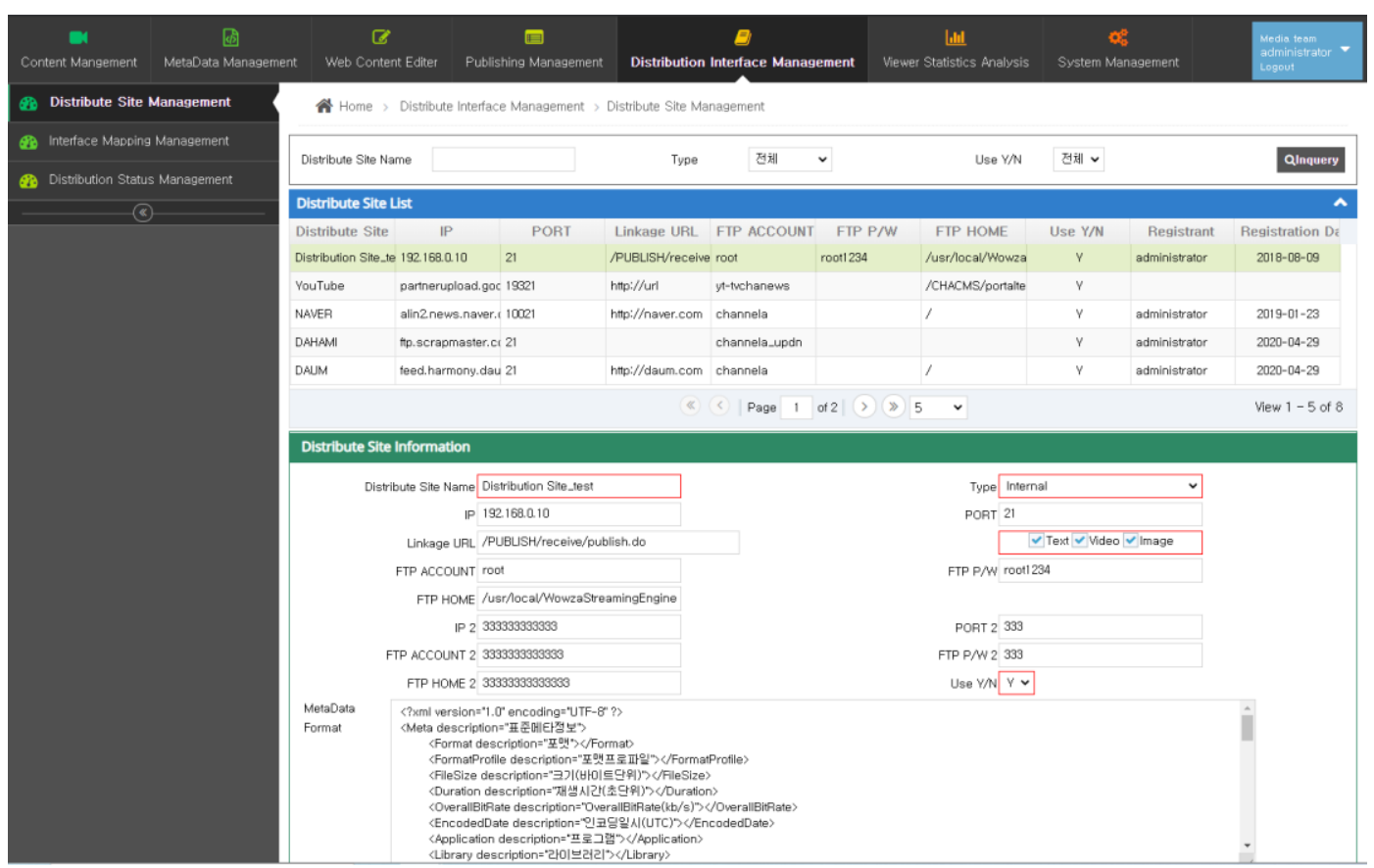

Fig. 10. Link Information Management Screen among systems through Distribution Information Management 
Development details of the content reproduction and publishing platform function materialized in this study are as shown in Table 2.

Table 2. Development Details of Platform

\begin{tabular}{|c|c|c|}
\hline \multicolumn{2}{|c|}{ Menu Configuration } & \multirow{2}{*}{ Detailed Description } \\
\hline Classification 1 & Classification 2 & \\
\hline \multirow{3}{*}{$\begin{array}{l}\text { Content } \\
\text { management part }\end{array}$} & Article management & $\begin{array}{l}\text { Provide the screen that can save and correct the metadata on the } \\
\text { text content, writer, preparation data, test content }\end{array}$ \\
\hline & Video management & $\begin{array}{l}\text { Manage the video content metadata information, video file } \\
\text { upload, file attribute information, and registration information }\end{array}$ \\
\hline & Image management & $\begin{array}{l}\text { Manage the image information inquiry, image upload, and the } \\
\text { metadata on the image }\end{array}$ \\
\hline \multirow{3}{*}{$\begin{array}{l}\text { Metadata } \\
\text { Management part }\end{array}$} & $\begin{array}{l}\text { Provider Information } \\
\text { management }\end{array}$ & $\begin{array}{l}\text { Manage the basic information of content provider and the content } \\
\text { and the advanced metadata. }\end{array}$ \\
\hline & Metadata information & $\begin{array}{l}\text { Provide the function to be able to register and correct the standard } \\
\text { attribute information of the multimedia contents }\end{array}$ \\
\hline & Mapping management & $\begin{array}{l}\text { Provide the function to be able to manage the mapping the } \\
\text { contents and standard metadata provided from the content } \\
\text { provider }\end{array}$ \\
\hline \multirow{2}{*}{$\begin{array}{l}\text { Web } \\
\text { content } \\
\text { Editor part }\end{array}$} & Web content editing & $\begin{array}{l}\text { Provide the function to be able to edit URL-based video file and } \\
\text { to combine more than one content }\end{array}$ \\
\hline & $\begin{array}{l}\text { Reproduction Request } \\
\text { history }\end{array}$ & Provide the information of video content edit request history \\
\hline \multirow{3}{*}{$\begin{array}{l}\text { Publishing } \\
\text { management part }\end{array}$} & $\begin{array}{l}\text { Publishing } \\
\text { information }\end{array}$ & $\begin{array}{l}\text { Can generate and correct new publishing content and provide the } \\
\text { function to preview, inquire the information list and to release the } \\
\text { relevant content to outside }\end{array}$ \\
\hline & Publishing format edit & $\begin{array}{l}\text { Provide the function to reproduce new contents such as video }+ \\
\text { image }+ \text { article, image }+ \text { article, etc. using the media information }\end{array}$ \\
\hline & Publishing history & $\begin{array}{l}\text { Provide the function to be able to inquire the information of the } \\
\text { contents released to external service system }\end{array}$ \\
\hline \multirow{3}{*}{$\begin{array}{l}\text { Distribution } \\
\text { management part }\end{array}$} & $\begin{array}{l}\text { Distribution } \\
\text { site management }\end{array}$ & $\begin{array}{l}\text { Provide the function to register ad manage the release site } \\
\text { information and linked metadata }\end{array}$ \\
\hline & $\begin{array}{l}\text { Interface } \\
\text { mapping management }\end{array}$ & $\begin{array}{l}\text { Provide the function to manage the mapping of metadata of the } \\
\text { reproduced contents in the site to be released }\end{array}$ \\
\hline & $\begin{array}{l}\text { Distribution } \\
\text { status management }\end{array}$ & $\begin{array}{l}\text { Provide the function to manage if the publishing contents are } \\
\text { distributed normally through the link to release site }\end{array}$ \\
\hline \multirow{3}{*}{$\begin{array}{l}\text { Viewer } \\
\text { statistics } \\
\text { analysis part }\end{array}$} & Content viewer log & $\begin{array}{l}\text { Provide the function to be able to inquire the viewing history } \\
\text { information of the contents reproduced and distributed by day, } \\
\text { week and month unit }\end{array}$ \\
\hline & $\begin{array}{l}\text { Content } \\
\text { viewer analysis }\end{array}$ & $\begin{array}{l}\text { Provide the function to analyze the contents service data such as } \\
\text { service frequency by user attribute and site of the viewed contents }\end{array}$ \\
\hline & Content viewer report & Provide the statistical data on the viewing history of contents \\
\hline
\end{tabular}


The interface items linked to outside are as shown in Table 3.

Table 3. Interface Development

\begin{tabular}{|c|c|}
\hline Interface Development & Description of Interface \\
\hline Source site meta transmission & Metadata transmission \\
\hline Streaming server link & Streaming server URL link \\
\hline Portal service link & Portal service distribution link \\
\hline YouTube link & YouTube Distribution Link \\
\hline SMR/POOQ Link & SMR/POOQ Distribution Link \\
\hline Media Portal Link & Media portal link \\
\hline
\end{tabular}

\section{Experiment}

In this chapter, to vitalize the online content distribution suggested in this study, the functions and the performance of the reproduction-based content publishing platform technology, which can reproduce and distribute the content based on the real-time content editing technology in URL unit using the standard-based broadcasting content distribution metadata technology and the streaming technology of the content subject to edit, and based on the consumer's consumption propensity analysis technology, were proven though the experiment. The test environment was composed of 1 platform server and 2 client PCs as shown in Fig. 11.

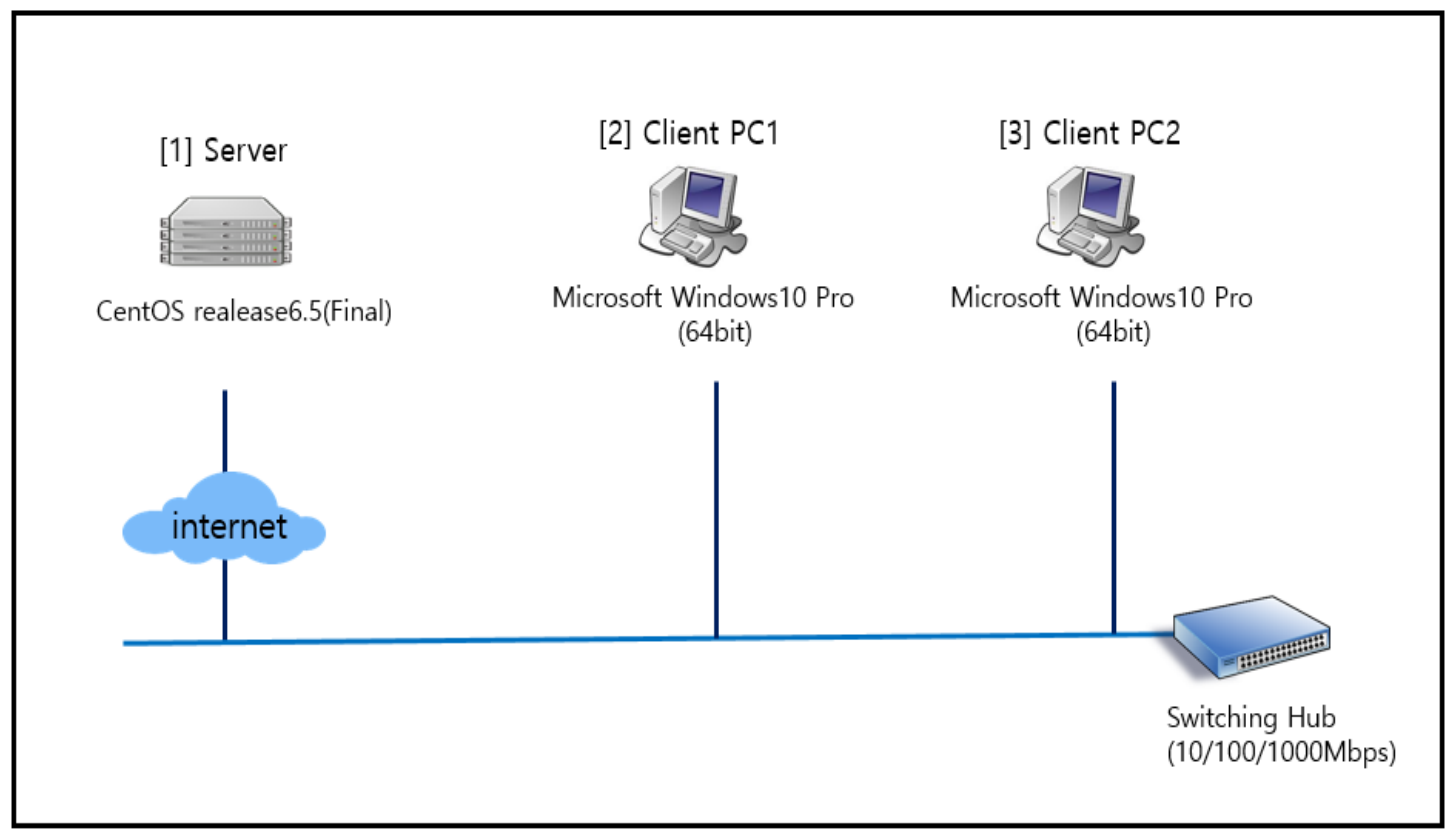

Fig. 11. Configuration of Test Environment

In the test environment for experiment, the detailed specification of the server and client equipments is as shown in Table 4. 
Table 4. Test Environment

\begin{tabular}{|c|c|c|c|c|c|c|}
\hline \\
\hline $\mathrm{NO}$ & Role & OS & $\mathrm{CPU}$ & Memory & Disk & Pre-Requisite \\
\hline 1 & Server & $\begin{array}{l}\text { CentOS } \\
\text { release6.5 } \\
\text { (Final) }\end{array}$ & $\begin{array}{l}\text { Intel Xeon } \\
\text { E5-2630 V3 } \\
\text { @ } 2.40 \mathrm{GHz}\end{array}$ & $32 \mathrm{~GB}$ & $3.6 \mathrm{~TB}$ & $\begin{array}{l}\text { - MySQL 8.42 } \\
\text { - JDK 1.8.0_65 } \\
\text { - Apache Tomcat } \\
7.0 .73 \\
\text { - FFMPEG } \\
\text { N-86244-gca616b0 } \\
\text { - Wowza Steaming } \\
\text { Engine 3.4.0 }\end{array}$ \\
\hline 2 & $\begin{array}{l}\text { Client } \\
\text { PC } 1\end{array}$ & $\begin{array}{c}\text { Windows } 10 \\
\text { Pro(64bit) }\end{array}$ & $\begin{array}{l}\text { Intel core } \\
\mathrm{i} 5-5200 \mathrm{U} \\
\text { @ } 2.20 \mathrm{GHz}\end{array}$ & $8 \mathrm{~GB}$ & $\begin{array}{c}\text { SSD } \\
128 \mathrm{~GB}\end{array}$ & $\begin{array}{l}\text { - Chrome } \\
\text { v71.0.3578.98 } \\
\text { - jMeter v5.0 } \\
\text { - Mediainfo 18.08.1 }\end{array}$ \\
\hline 3 & $\begin{array}{l}\text { Client } \\
\text { PC2 }\end{array}$ & $\begin{array}{l}\text { Windows } 10 \\
\text { home(64bit) }\end{array}$ & $\begin{array}{l}\text { Intel core } \\
\text { i5-3230M } \\
@ 2.60 \mathrm{GHz}\end{array}$ & $8 \mathrm{~GB}$ & $\begin{array}{c}\text { SSD } \\
120 \mathrm{~GB}\end{array}$ & - jMeter v5.0 \\
\hline
\end{tabular}

For the performance standard of server, the experiment was conducted after building the test environment to perform the operation in the existing server performance. The test was performed to see if the video, image and article, which are the publishing contents edited and combined in the HTML format in the web browser of the platform materialized with this study would be output normally in the form of reproduction and verified that it is working normally through the performance test by TTA, which is the official Korean test certification institution. First test is the response time test of the platform and is to see if the average response time in the load test for 3 minutes with total 200 threads (100 threads * 2 clients) in the 5 Requests of jMeter client is within 1 second and in the results shown in Table 5, it was confirmed that minimum $474.5 \mathrm{~ms}$, maximum $596.0 \mathrm{~ms}$ and average $543.4 \mathrm{~ms}$.

Table 5. Average Response Time when accessing 200 persons at the same time

\begin{tabular}{|c|c|c|}
\hline \multicolumn{3}{|c|}{ (Unit: $\mathrm{ms}$ ) } \\
\hline Request type & 1 time & 2 time \\
\hline Auth & $474.5^{* *}$ & 543.0 \\
\hline Year & 503.0 & 546.0 \\
\hline Month & 574.5 & $596.0 *$ \\
\hline Hour & 574.5 & 553.5 \\
\hline Second & 500.0 & 569.0 \\
\hline average & 525.3 & 561.5 \\
\hline Total average & 543.4 \\
\hline \multicolumn{2}{|c|}{ max value* ${ }^{*}$ min value** } \\
\hline
\end{tabular}

Second test was to see if the video, image and article contents were processed through the materialized editor and output normally in the web browser in HTML format and the results 
were verified as shown in Fig. 12.

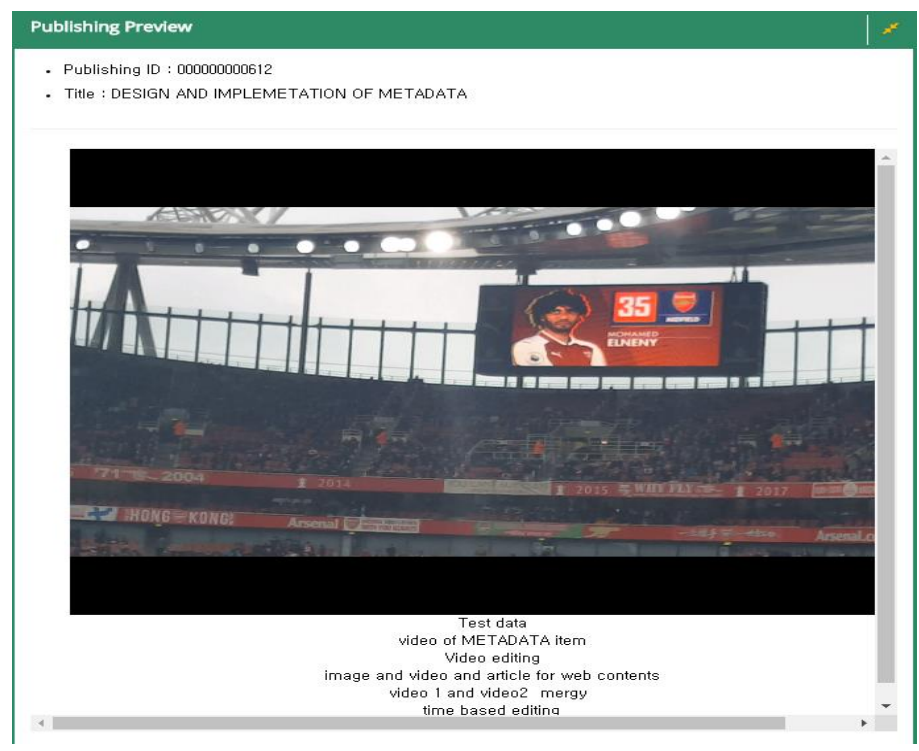

Fig. 12. Article and Video Combination Test Result

Third test was to test the video contents completed the reproduction-based content publishing work by combining the first video of Bus content and the second video of UCC content using URL-based web editor technology. It was verified that PublishingID 000000000613, Title Bus content and UCC content merge are working normally as shown in Fig. 13.

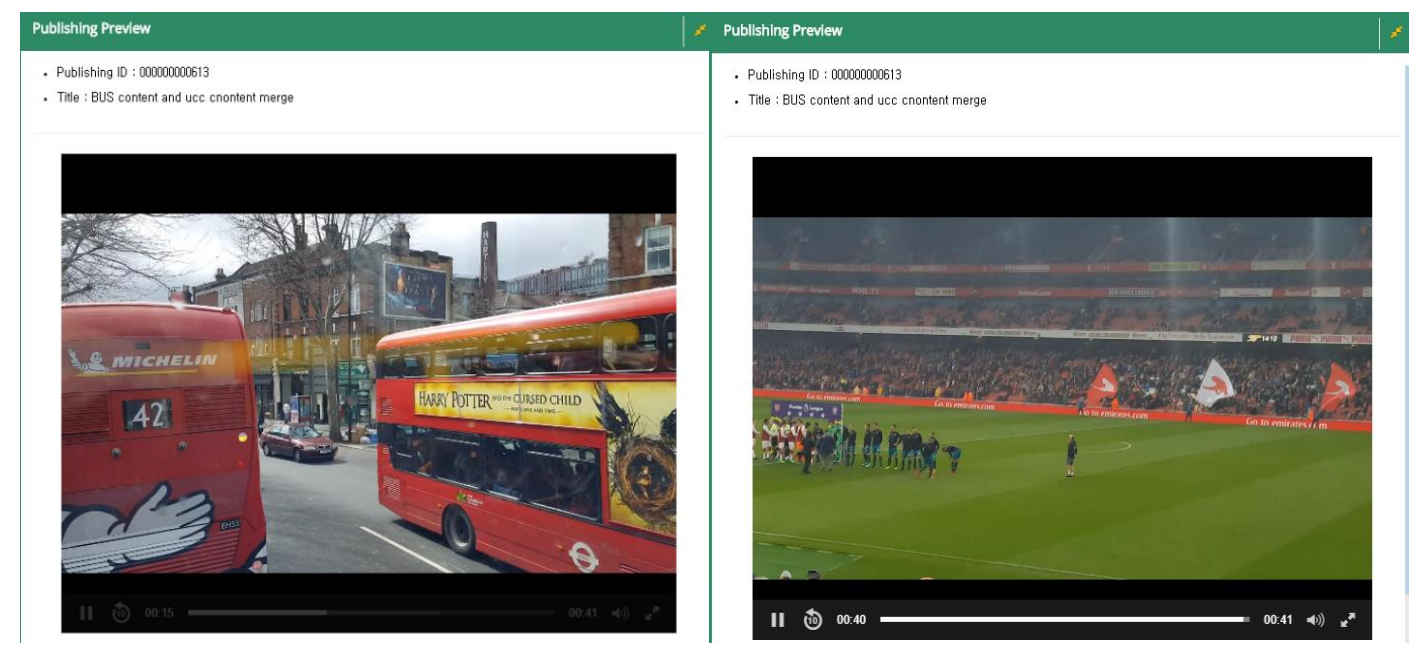

Fig. 13. Screen that playback the content by combining two contents into one

Fourth test was to save the information, which the distributed content was viewed in the service after content distribution, and to analyze the consumer's propensity automatically as shown in Fig. 14. 


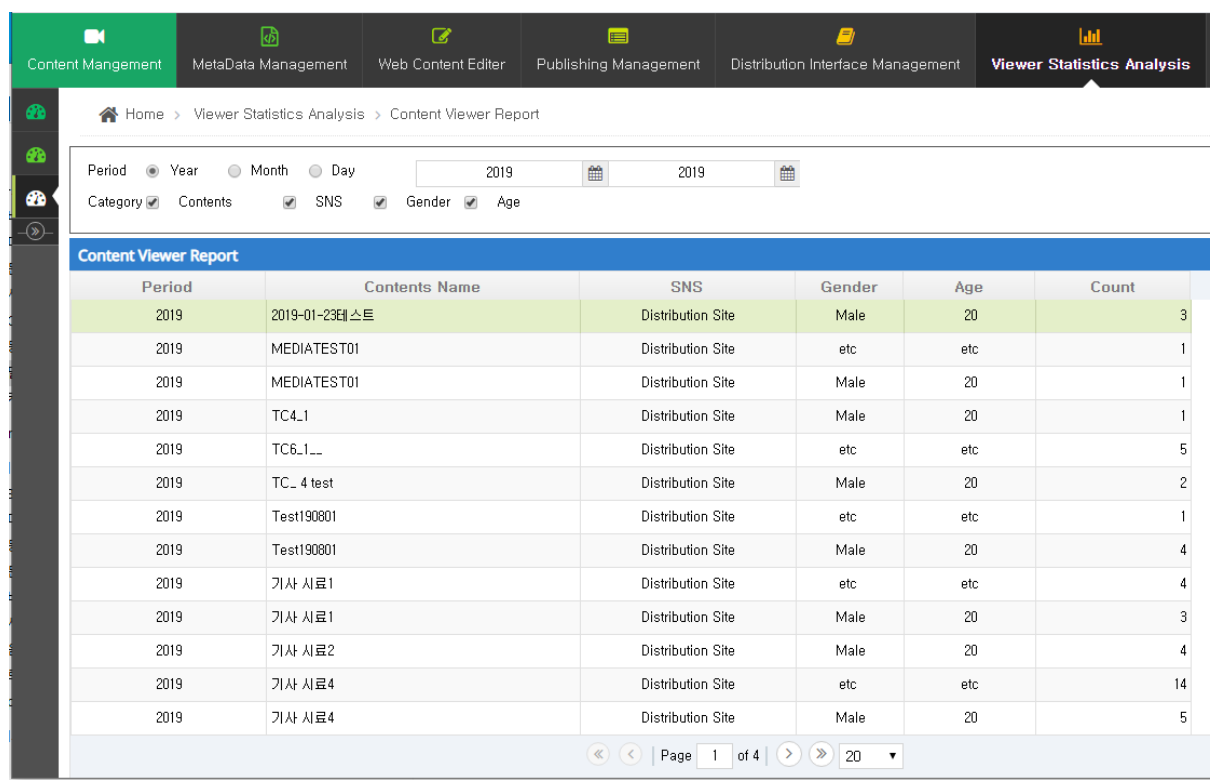

Fig. 14. Consumer's Viewing History Information Screen

The platform suggested in this study was compared with 4 existing platforms based on the major functions of the suggested platform. The existing platforms mostly extract and manage the metadata information but do not use it as mapping information to provide the service providers. In addition, the video editing technology used the separate editor and provided the transcoding function rather than the editing. It was verified that for the link to the service site, they used the link, which was developed separately, and do not have mapping function in the meta information. And for the log analysis function of the distributed content, they provided the major statistical function from the site operated independently and do not provide the analysis on the content consumer's propensity. Below Table $\mathbf{6}$ shows the comparison between the method suggested by this study and the functional aspects provided by existing platforms.

Table 6. Function Comparison with Existing Platforms

\begin{tabular}{|c|c|c|c|c|c|}
\hline \multirow{2}{*}{ Function } & \multicolumn{4}{|c|}{ Existing Platforms } & \multirow{2}{*}{$\begin{array}{l}\text { Suggeste } \\
\text { d } \\
\text { Platform }\end{array}$} \\
\hline & $\mathrm{Ko}^{* *}$ & $\mathrm{Me}^{* *}$ & $\mathrm{Ma}^{* *}$ & $\mathrm{AM}^{* *}$ & \\
\hline $\begin{array}{l}\text { Extract the metadata and } \\
\text { support the mapping function }\end{array}$ & $\begin{array}{l}\text { Management } \\
\text { only }\end{array}$ & Provided & Provided & $\begin{array}{c}\text { Not } \\
\text { managed }\end{array}$ & Provided \\
\hline $\begin{array}{l}\text { Provide the URL } \\
\text { - based real-time video editing } \\
\text { function }\end{array}$ & $\begin{array}{l}\text { Not } \\
\text { provided }\end{array}$ & Provided & $\begin{array}{c}\text { Not } \\
\text { supported }\end{array}$ & $\begin{array}{c}\text { Not } \\
\text { supported }\end{array}$ & Provided \\
\hline $\begin{array}{l}\text { Function to make the size by } \\
\text { distribution site as template } \\
\text { by matching the metadata } \\
\text { by linked site }\end{array}$ & $\begin{array}{c}\text { Not } \\
\text { provided }\end{array}$ & $\begin{array}{l}\text { Individual } \\
\text { link }\end{array}$ & $\begin{array}{c}\text { Not } \\
\text { provided }\end{array}$ & $\begin{array}{l}\text { Individual } \\
\text { link }\end{array}$ & Provided \\
\hline $\begin{array}{l}\text { Function to analyze the distribution } \\
\text { log of distributed content and } \\
\text { consumption } \\
\text { propensity }\end{array}$ & Provided & $\begin{array}{c}\text { Not } \\
\text { provided }\end{array}$ & $\begin{array}{c}\text { Not } \\
\text { provided }\end{array}$ & Provided & Provided \\
\hline
\end{tabular}




\section{Conclusion}

In this study, to vitalize of the online content distribution, the reproduction-based content publishing platform technology was designed and materialized, which can reproduce and distribute the content based on the real-time content editing technology in URL unit using the standard-based broadcasting content distribution metadata technology and the streaming technology of the content subject to edit, and based on the consumer's consumption propensity analysis technology. In addition, to verify the functions and the performance, the test was performed and in the result, it was verified that they are working normally. To prove the excellence of the suggested platform, the comparative analysis with existing 4 platforms was conducted. The function test was performed for total 4 items and the results showed that since it was verified that the suggested platform supported all 4 functions, the excellence of suggested solution was proven. In addition, through this study, it was known that the content business operators developed and are using the platform for the independent service.

Recently, the high-definition contents are being produced by the development of video filming equipment and the utilization range and frequency of the multimedia content are being increased by the development of IT technology and mobile devices. At the same time, the performance degradation problem occurred when editing the video contents is pointed out. In future, to improve the performance degradation problem when editing, the high speed parallel processing technology will be researched together with more advanced research on the platform, which can generate and distribute the contents through the reprocessing multimedia contents easily and conveniently.

\section{References}

[1] M. Abramovici, J. C. Göbel, and M. Neges, "Smart Engineering as Enabler for the $4^{\text {th }}$ Industrial Revolution," Integrated Systems: Innovations and Applications, pp. 163-170, 2015. Article (CrossRef Link)

[2] National IT Industry Promotion Agency, "2018 International Digital Content Market Research," vol. 18, pp. 20, 2018. Article (CrossRef Link)

[3] A. Helmond, "The Platformization of the Web: Making Web Data Platform Ready," Social Media + Society, p. 1-11, Sep. 2015. Article (CrossRef Link)

[4] E. Nygren, R. K. Sitaraman, and J. Sun, "The Akamai network," ACM SIGOPS Operating Systems Review, vol. 44, no. 3, pp. 2-19, Aug. 2010. Article (CrossRef Link)

[5] TTA Standard, "Metadata Element and Format for Broadcast Content Distribution," TTAK.KO-10.0730, 2014. Article (CrossRef Link)

[6] D. Broeder, D. V. Uytvanck, M. Gavrilidou, T. Trippel, and M. Windhouwer, "Standardizing a component metadata infrastructure," in Proc. of the $8^{\text {th }}$ International Conference on Language Resources and Evaluation, pp. 1387-1390, 2012. Article (CrossRef Link)

[7] M. Agiwal, A. Roy, and N. Saxena, "Next Generation 5G Wireless Networks: A Comprehensive Survey," IEEE Communications Surveys \& Tutorials, vol. 18, no. 3, pp. 1617-1655, 2016.

Article (CrossRef Link)

[8] L. Jiang, G. Feng, and S. Qin, "Cooperative content distribution for 5G systems based on distributed cloud service network," in Proc. of IEEE International Conference on Communication Workshop (ICCW), pp. 1125-1130, 2015. Article (CrossRef Link)

[9] Z. Su and Q. Xu, "Content distribution over content centric mobile social networks in 5G," IEEE Communications Magazine, vol. 53, no. 6, pp. 66-72, June 2015. Article (CrossRef Link)

[10] J. E. Lim, O. H. Choi, H. S. Na, and D. K. Baik, "A method for contents management using extended metadata in CDN,"Journal of Digital Contents Society, vol. 9, no. 4, pp. 725-733, 2008. Article (CrossRef Link)

[11] S. D. Park and S. H. Park, "Instructional Methodology for Video Editing in Image Content 
Production," Journal of the Korea Society of Computer and Information, vol. 19, no. 12, pp. 39-48, Dec. 2014. Article (CrossRef Link)

[12] S. Amara and R. R. Subramanian, "Collaborating personalized recommender system and content-based recommender system using TextCorpus," in Proc. of the $6^{\text {th }}$ International Conference on Advanced Computing and Communication Systems (ICACCS), 2020. Article (CrossRef Link)

[13] MediaArea. [Online]. Available: https://mediaarea.net

[14] FFmpeg. [Online]. Available: https://www.ffmpeg.org

[15] Y. Zhou, D. Wilkinson, R. Schreiber, and R. Pan, "Large-Scale Parallel Collaborative Filtering for the Netflix Prize," in Proc. of International Conference on Algorithmic Aspects in Information and Management, vol. 5034, pp. 337-348. Article (CrossRef Link)

[16] J. Davidson, B. Liebald, J. Liu, P. Nandy, T. V. Vleet, U. Gargi, S. Gupta, Y. He, M. Lambert, and B. Livingston, "The YouTube video recommendation system," in Proc. of the $4^{\text {th }}$ ACM conference on Recommender, 2010. Article (CrossRef Link)

[17] J. Wei, J. He, K. Chen, Y. Zhou, and Z. Tang, "Collaborative filtering and deep learning based recommendation system for cold start items," Expert Systems with Applications, vol. 69, pp. 29-39, Mar. 2017. Article (CrossRef Link)

[18] J. H. Park, B. K. Kim, Y. H. Lee, M. W. Lee, M. O. Jung, and J. H. Kang, "Metadata Management System for XML-based Digital Broadcasting,"Journal of KIISE: Computing Practices and Letters, vol. 11, no. 4, pp. 334-348, 2005. Article (CrossRef Link) 


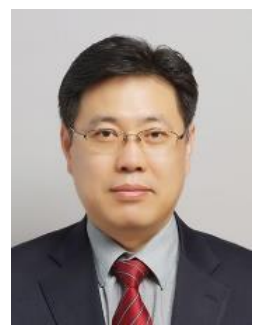

Byung-Duck Lee is researher of Visual Information Processing Lab in the division of distributed parallel processing at Korea University in 2017 2019. He received the B.S. degree in Computer Science from Soonchunhyang University, Korea in 1989 1996. He was a computer team leader of the Taekwang Inc. in 1995 2006, and was the CTO of the Celrun Inc. in 2007 2011, and was the CTO of the Uracel inc. in 2011 2012. His research interests include software engingeering, parallel processing computing, Bigdata, AI, digital contents management, and mobile application.

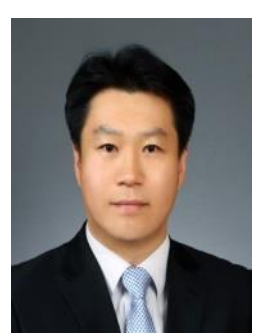

Keun-Ho Lee is a professor in the division of Information Communication Technology at Baekseok University. He received the B.S. degree in Computer Science from Soonchunhyang University, Korea in 1998, the M.S. degree in Electronic Commerce from Soonchunhyang University, Korea in 2001, the Ph.D. degree in Computer Science from Korea University in 2006. He was the manager of the Samsung Electronic in 2006 2010. His research interests include IoT, Physical Security, Intelligent Vehicle, Biometric, AI, Blockchain, Bigdata and Information Security.

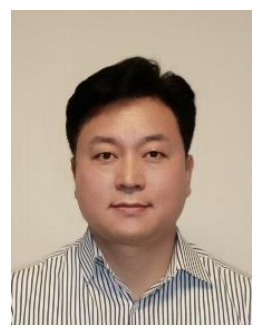

Seong-Soo Han is a professor in the division of Liberal Studies at Kangwon National University. Before joining Kangwon National University in 2019, he was a professor at Soonchunhyang University durig 2018 2019. He received the B.S. degree in Information and Communication Engineering from Gyeongsang National University, He received the M.S. degree in Information and Communication Engineering from Soonchunhyang University, Korea in 2005, the Ph.D. degree in Visual Information Processing from Korea University in 2018. He was a Director of the Orion Technology in 2015 2016. His research interests include computer education, ubiquitous computing, AI, blockchain, deep learning and distributed parallel processing.

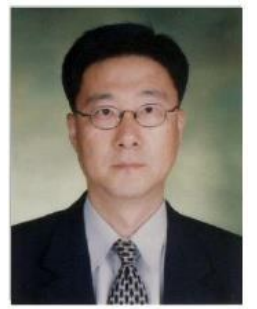

Chang-Sung Jeong(Corresponding Author) is a professor at the dept. of EE/CE at Korea University. He received his MS.(1985) and Ph.D.(1987) from Northwestern University, and B.S.(1981) from Seoul National University. Before joining Korea University, he was a professor at POSTECH during 1982-1992. He was on editorial board for Journal of Parallel Algorithms and Application in 1992-2002. Also, he has been working as a chairman of Collaborative Supercomputing Group in GFK(Global Forum in Korea) since 2001, and a chairman of Computer Chapter at Seoul Section of IEEE region 10 since 2000. His research interests include distributed concurrent computing, grid computing, and collaborative ubiquitous computing. 